Original Article

\title{
Pediatric Complex Appendicitis are there Predictors of Postoperative Outcomes?
}

\author{
Nadav Mizrahi ${ }^{1,2 *}$, Inbal Samuk ${ }^{2,3}$, Shai Ashkenazi ${ }^{2,4}$, Gabriel Chodick2 ${ }^{2}$ Enrique Freud ${ }^{2,3}$ and Gilat Livni ${ }^{2,3}$ \\ ${ }^{1}$ Department of Pediatrics B, Schneider Children's Medical Center of Israel, Israel \\ ${ }^{2}$ Sackler Faculty of Medicine, Tel Aviv University, Israel \\ ${ }^{3}$ Department of Pediatric and Adolescent Surgery, Schneider Children's Medical Center of Israel, Israel \\ ${ }^{4}$ Department of Pediatrics and Unit of Pediatric Infectious Diseases, Schneider Children's Medical Center of Israel, Israel
}

\begin{abstract}
Introduction: Acute appendicitis is the most common condition necessitating abdominal emergency surgery. We aimed to identify preoperative parameters predictive of postoperative complications in children with complicated appendicitis.

Methods: The database of a tertiary pediatric medical center was retrospectively reviewed for patients pathologically diagnosed with complex appendicitis in 2012-2015. Admission parameters were evaluated for their predictive value for postoperative complications using logistic regression analysis.

Results: Multivariable analysis of the 102 eligible cases yielded 2 predictors of longer hospital stay (as continuous variable): C-reactive protein $>10 \mathrm{mg} / \mathrm{dL}$ at presentation (OR 20.657; 95\% Cl 1.790-238.369, $P=0.016$ ) and fever for $\geq 3$ days before admission (OR 6.167; $95 \% \mathrm{Cl} 1.211-31.393, P=0.03$ ). Type of pathogen isolated on peritoneal culture had no effect on postoperative outcomes. In 12 patients (11.1\%) diagnosed intraoperatively with simple appendicitis and treated accordingly, there were no postoperative complications.

Conclusions: Prolonged hospital stay after surgery for complex appendicitis may be predicted by C-reactive protein level at admission and duration of pre-admission fever. Attention to these factors may help clinicians identify children at risk who may benefit from early detection. Obtaining peritoneal cultures need not be obtained routinely. The operative diagnosis might better predict outcomes than the pathological diagnosis. Pathologically gangrenous appendicitis that is diagnosed intraoperatively as simple appendicitis may be treatable with acute/simple appendicitis protocols.
\end{abstract}

\section{Keywords}

Appendicitis, Complex appendicitis, Appendectomy, Complications, Peritoneal cultures

\section{Introduction}

Acute appendicitis is the most common condition necessitating abdominal emergency surgery. Cases are classified as simple or complex on the basis of the intraoperative and histopathological findings. Appendicitis is considered complex if the appendix is perforated with a visible hole. Some authors include gangrenous appendicitis (micro perforation) with no visible transmural defect in this category as well $[1,2]$. Complex appendicitis is associated with a higher rate of re-intervention and longer hospital stay than simple appendicitis, exerting a heavy burden on both the patient and the pediatric healthcare system $[3,4]$. Therefore, early identification of patients at risk is important. However, factors that can reliably predict postoperative complications in the pediatric population have not been well defined. In addition, the usefulness of intraoperative peritoneal cultures in this context is unclear, and there is evidence in the literature that challenges their routine performance [5-7].
The main goal of the present study was to identify predictors of postoperative complications of complex appendicitis in children. The secondary goals were to analyze complication rates as function of peritoneal culture results and discrepancies between the surgical and pathological diagnoses.

*Corresponding author: Nadav Mizrahi, MD, Department of Pediatrics B, Schneider Children's Medical Center of Israel, $14 \mathrm{Ka}-$ plan Street, Petach Tikva 4920235, Israel, Tel: +972-3-925-3681, Fax: +972-3-925-3045

Accepted: October 03, 2019

Published online: October 05, 2019

Citation: Mizrahi N, Samuk I, Ashkenazi S, et al. (2019) Pediatric Complex Appendicitis are there Predictors of Postoperative Outcomes?. Arch Pediatr Surg 3(1):53-58 


\section{Methods}

\section{Study population and study design}

The database of a tertiary pediatric medical center was retrospectively reviewed for all patients treated for complex appendicitis between November 2012 and March 2015. Only patients aged 18-years or less with a pathologically confirmed diagnosis of a perforated or gangrenous appendix were included. The study was approved by the Institutional Review Board with waiver of informed consent.

\section{Data collection}

The following data were collected for the study from the individual medical files: demographic parameters, presenting symptoms, duration of symptoms, laboratory results (complete blood count, C-reactive protein level), findings on the surgery and pathology reports, type and duration of antibiotic treatment, peritoneal cultures results (Enterobacteriacea spp., Pseudomonas spp., Gram-positive bacteria), and complications during the postoperative course (intra-abdominal abscess formation, wound site infection, and duration of hospital stay.

\section{Outcome measures}

Three outcomes were monitored in this study: lengths of hospital stay (days), intra-abdominal abscess formation as demonstrated with abdominal imaging (ultrasound/computed tomography) and superficial or deep incisional surgical site infection defined and classified using published Centers for Disease Control and Prevention criteria [8]. Outcome measures included significant associations between preoperative parameters and postoperative outcome; effect of the culture results on outcome; and effect of discrepancies between the surgical and pathological diagnosis on outcome.

\section{Statistical analysis}

Preoperative factors found to be significantly associated with postoperative complications on univariate analysis $(P$ $<0.05$ ) were entered into a multivariable model to analyze their independent risk effect. Chi-square test with Bonferroni correction was used to compare categorical variables and analysis of variance (ANOVA) was used to compare age distribution between groups. Multivariable logistic regression was used to identify significant predictors of postoperative complications. A $P$ value $<0.05$ was considered statistically significant. Values are shown as mean \pm standard deviation.

\section{Results}

\section{Characteristics of the study population}

Of the 588 children who underwent appendectomy during the study period, 106 were histologically classified as having complex appendicitis. Four of them were excluded from the analysis because of missing data in the medical chart. The remaining 102 children formed the study group (Table 1).

There were 61 male (59.8\%) and 41 female patients of mean age $10.18 \pm 4.34$ years at presentation (range 7 months
Table 1: Epidemiologic and preoperative clinical data of 102 children with complex appendicitis.

\begin{tabular}{|c|c|}
\hline Characteristics & $\mathrm{N}(\%) /$ mean $\pm \mathrm{SD}^{*}$ \\
\hline \multicolumn{2}{|l|}{ Demographics } \\
\hline Male sex, n (\%) & $61(59.8)$ \\
\hline Age (years), mean \pm SD & $10.18 \pm 4.34$ \\
\hline$\leq 1 \mathrm{yr}, \mathrm{n}(\%)$ & $1(0.98)$ \\
\hline $1-3 \mathrm{yr}, \mathrm{n}(\%)$ & $5(4.9)$ \\
\hline 4-6 yr, n (\%) & $12(11.76)$ \\
\hline $7-12$ yr n (\%) & $45(44.12)$ \\
\hline $13-18$ yr, n (\%) & 39 (38.24) \\
\hline \multicolumn{2}{|l|}{ Presenting symptoms } \\
\hline Abdominal pain & $97(95.1)$ \\
\hline Nausea/vomiting & $76(74.5)$ \\
\hline Fever $\left(\geq 38^{\circ} \mathrm{C}\right)$ & $51(50)$ \\
\hline Diarrhea & 20 (19.6) \\
\hline Symptom duration (days) & $2.34 \pm 1.5$ \\
\hline Fever duration (days) & $2 \pm 1.2$ \\
\hline \multicolumn{2}{|l|}{ Laboratory tests } \\
\hline$W B C(K / \mu L)$ & $16.73 \pm 5.3$ \\
\hline Neutrophils $(\mathrm{K} / \mu \mathrm{L})$ & $13.9 \pm 4.9^{* *}$ \\
\hline CRP (mg/dL) & $10.04 \pm 8.12^{* * *}$ \\
\hline Hemoglobin (g/dL) & $12.9 \pm 1.3$ \\
\hline Platelets $(\mathrm{K} / \mu \mathrm{L})$ & $299.9 \pm 69.1$ \\
\hline
\end{tabular}

WBC: White Blood Cells; CRP: C-Reactive Protein; ${ }^{*}$ Mean \pm SD for continuous variables; ${ }^{* *}$ Neutrophils count was available for 92 patients; ${ }^{* *}$ CRP levels were available for 100 patients.

Table 2: Microorganisms isolated from peritoneal fluid specimens from 81 children.

\begin{tabular}{|l|l|}
\hline Microorganism & N (\%) \\
\hline Gram-negative bacteria & $41(45.6)$ \\
\hline Enterobacteriaceae & $33(36.7)$ \\
\hline Escherichia coli & $31(34.4)$ \\
\hline Proteus spp. & $2(2.2)$ \\
\hline Klebsiella spp. & $3(3.3)$ \\
\hline Citrobacter freundii & $1(1.1)$ \\
\hline Pseudomonas aeruginosa & $15(16.7)$ \\
\hline Bacteroides fragilis & $2(2.2)$ \\
\hline Gram-positive bacteria & $13(14.4)$ \\
\hline Streptococcus spp. & $9(10)$ \\
\hline Group milleri & $4(4.4)$ \\
\hline Viridans streptococci & $3(3.3)$ \\
\hline B-hemolytic & $2(2.2)$ \\
\hline Enterococcus spp. & $2(2.2)$ \\
\hline Staphylococcus spp. & $2(2.2)$ \\
\hline Total positive & 90 \\
\hline
\end{tabular}


to 17.9 years). Preadmission symptoms included nausea or vomiting in $74.5 \%$ of patients, fever $\left(\geq 38{ }^{\circ} \mathrm{C}\right)$ in $50 \%$ and diarrhea in $19.6 \%$. The mean duration of symptoms was $2.34 \pm$ 1.5 days (range 1 to 7 days). Mean laboratory values of the cohort at admission were as follows: white blood cell count, $16.73 \pm 5.3 \mathrm{~K} / \mu \mathrm{L}$; absolute neutrophil count (documented in 92 children), $13.9 \pm 4.9 \mathrm{~K} / \mu \mathrm{L}$; CRP level (documented in in 100 children), $10.04 \pm 8.12 \mathrm{mg} / \mathrm{dL}$. Open appendectomy was performed in 86 children (84.3\%) and laparoscopic appendectomy in $15(14.7 \%)$, with one conversion to open surgery due to multiple adhesions.

\section{Microbiology and antibiotic treatment}

Ninety peritoneal cultures were obtained from 81 children, of which 45 (50\%) were positive (Table 2). Isolates of Escherichia coli were identified in 31 cultures (34.4\%), all sensitive to cephalosporin. There were no isolates of extended-spectrum beta lactamases or carbapenem-resistant Enterobacteriaceae. Isolates of Pseudomonas aeruginosa were identified in 15 cultures (16.7\%), all sensitive to piperacillin-tazobactam, ceftazidime, and aminoglycosides. Gram-positive bacteria were identified in 13 cultures (14.4\%), including 9 isolates of streptococcal species. Coagulase-negative Staphylococcus was isolated in 2 cases; this finding was interpreted as sample contamination.

All children but one were treated empirically with a combination of third- generation cephalosporin and metronidazole for a mean duration of $4.84 \pm 1.97$ days (range 1 to 11 days), according to the institutional protocol (Figure 1). The outstanding child received cephalosporin monotherapy because he presented with only mild nonspecific signs and symptoms. In 22 children ( $21.5 \%$ ), treatment was modified in accordance with the culture results and clinical findings; most (19 children) were switched to piperacillin-tazobactam. The median duration of total treatment was $6.9 \pm 4.8$ days (range 1 to 31 days).

\section{Postoperative complications}

Fever developed postoperatively in 38 children (37.3\%).

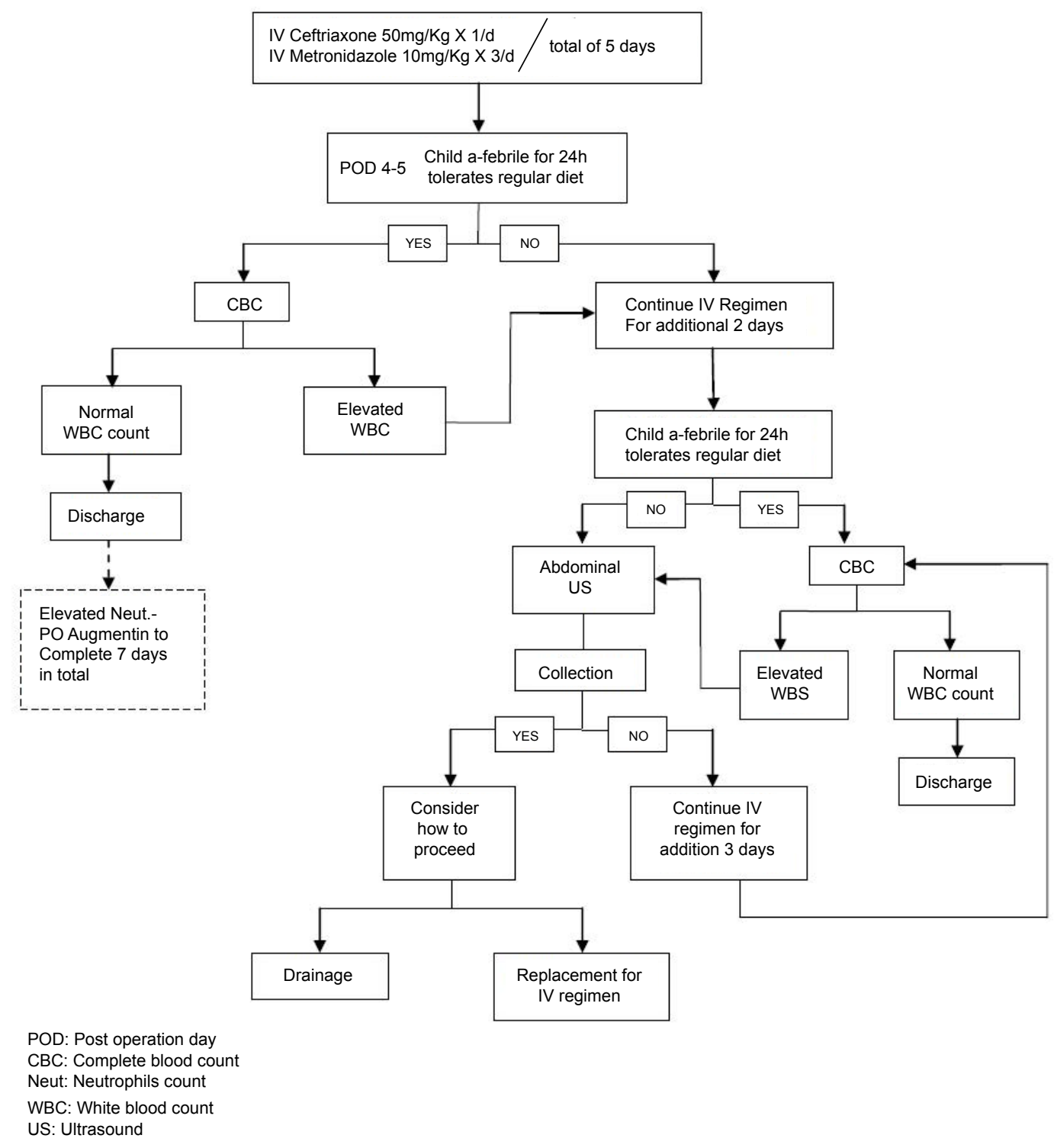

Figure 1: Institutional protocol of treating complicated appendicitis. 
Citation: Mizrahi N, Samuk I, Ashkenazi S, et al. (2019) Pediatric Complex Appendicitis are there Predictors of Postoperative Outcomes?. Arch Pediatr Surg 3(1):53-58

Table 3: Association between epidemiological, clinical and laboratory parameters and duration of hospital stay.

\begin{tabular}{|c|c|c|c|c|c|}
\hline \multirow[t]{2}{*}{ Parameters } & \multirow{2}{*}{$\begin{array}{l}\text { No. } \\
\text { patients }\end{array}$} & \multicolumn{3}{|c|}{$\begin{array}{l}\text { Duration of hospitalization } \\
\text { (days) }\end{array}$} & \multirow[t]{2}{*}{$P$ value } \\
\hline & & Mean & SD & Median & \\
\hline \multicolumn{6}{|c|}{ Demographic parameters } \\
\hline \multicolumn{6}{|l|}{ Sex } \\
\hline Male & 61 & 7.44 & 4.64 & 6 & \multirow{2}{*}{0.847} \\
\hline Female & 41 & 7.24 & 5.7 & 5 & \\
\hline \multicolumn{6}{|l|}{ Age (years) } \\
\hline$<5$ & 18 & 9.39 & 5.14 & 8 & \multirow{3}{*}{0.174} \\
\hline 11-Jun & 45 & 6.87 & 5.41 & 5 & \\
\hline 18-Dec & 39 & 7 & 4.5 & 6 & \\
\hline \multicolumn{6}{|c|}{ Symptom duration (days) } \\
\hline$<3$ & 65 & 6.6 & 4.91 & 5 & \multirow{3}{*}{0.027} \\
\hline 5-Mar & 32 & 8.12 & 4.32 & 7 & \\
\hline$\geq 6$ & 5 & 12.4 & 8.5 & 9 & \\
\hline \multicolumn{6}{|l|}{ Symptoms } \\
\hline \multicolumn{6}{|c|}{ Nausea/vomiting } \\
\hline Yes & 76 & 7.12 & 4.74 & 6 & \multirow{2}{*}{0.775} \\
\hline No & 26 & 7.45 & 5.2 & 5 & \\
\hline \multicolumn{6}{|c|}{ Abdominal pain } \\
\hline Yes & 97 & 14.6 & 3.51 & 15 & \multirow{2}{*}{0.001} \\
\hline No & 5 & 6.99 & 4.86 & 5 & \\
\hline \multicolumn{6}{|l|}{ Fever } \\
\hline Yes & 51 & 5.69 & 3.31 & 5 & \multirow{2}{*}{$<0.001$} \\
\hline No & 51 & 9.04 & 5.93 & 7 & \\
\hline \multicolumn{6}{|c|}{ Fever duration (days) } \\
\hline 1 & 77 & 6.01 & 3.48 & 5 & \multirow{3}{*}{$<0.001$} \\
\hline 2 & 8 & 11.38 & 7.13 & 8.5 & \\
\hline$\geq 3$ & 17 & 11.59 & 6.81 & 11 & \\
\hline \multicolumn{6}{|c|}{ Laboratory variables } \\
\hline \multicolumn{6}{|l|}{$\mathrm{WBC}(\mathrm{K} / \mu \mathrm{L})$} \\
\hline$<15$ & 37 & 8.14 & 6.11 & 6 & \multirow{3}{*}{0.511} \\
\hline $15-20$ & 41 & 6.98 & 5.45 & 5 & \\
\hline$>20$ & 24 & 6.83 & 4.14 & 5 & \\
\hline \multicolumn{6}{|c|}{ Neutrophils $(\mathrm{K} / \mu \mathrm{L})$} \\
\hline$<10$ & 21 & 7.29 & 4.78 & 7 & \multirow{2}{*}{0.85} \\
\hline$\geq 10$ & 71 & 7.54 & 5.46 & 5 & \\
\hline \multicolumn{6}{|l|}{ CRP (mg/dL) } \\
\hline$<2$ & 17 & 5.18 & 2.19 & 5 & \\
\hline 5-Feb & 18 & 5.44 & 3.09 & 5 & 0.001 \\
\hline 10-May & 21 & 6.38 & 2.84 & 6 & 0.001 \\
\hline$>10$ & 44 & 9.66 & 6.39 & 7.5 & \\
\hline
\end{tabular}

There were 3 cases $(2.9 \%)$ of wound site infections, all after open appendectomy, and 5 cases (4.9\%) of intra-abdominal abscess formation, defined as an organized collection
Table 4: Multivariable analysis of predictors of longer hospital stay in 102 children with complex appendicitis.

\begin{tabular}{|l|l|l|l|}
\hline \multicolumn{2}{|l|}{} & OR (95\% Cl) & P value \\
\hline \multicolumn{2}{|l|}{ Sex (female vs. male) } & $3.975(0.858-18.406)$ & 0.078 \\
\hline \multicolumn{2}{|l|}{ Age (per 1 year) } & $0.974(0.822-1.155)$ & 0.756 \\
\hline \multirow{3}{*}{ CRP (< 2 vs.) } & 5-Feb & $1.121(0.057-22.018)$ & 0.942 \\
\cline { 2 - 4 } & $10-M a y$ & $1.041(0.045-24.222)$ & 0.986 \\
\cline { 2 - 4 } & $>10$ & $20.657(1.790-238.369)$ & 0.016 \\
\hline
\end{tabular}

Fever duration (vs. 1)

\begin{tabular}{|l|l|l|l|}
\hline & 2 days & $2.837(0.305-26.43)$ & 0.36 \\
\hline & $\geq 3$ days & $6.167(1.211-31.393)$ & 0.03 \\
\hline Abdominal pain & $5.784(0.951-35.163)$ & 0.49 \\
\hline
\end{tabular}

Table 5: Comparison of surgical and pathological findings.

\begin{tabular}{|l|l|l|}
\hline \multirow{2}{*}{ Diagnosis } & \multicolumn{2}{|l|}{ N (\%) } \\
\cline { 2 - 3 } & Surgical & Pathological \\
\hline $\begin{array}{l}\text { Simple appendicitis (acute/ } \\
\text { phlegmonous) }\end{array}$ & $12(11.7)$ & - \\
\hline Complex appendicitis & $90(88.3)$ & $100(98)^{*}$ \\
\hline Gangrenous & $45(44.1)$ & $66(64.7)$ \\
\hline Perforated & $35(34.3)$ & $29(28.4)$ \\
\hline Abscess & $10(9.8)$ & $5(4.9)$ \\
\hline
\end{tabular}

${ }^{*}$ Additional 2 cases w/o pathology report available.

confirmed on imaging studies on $6-7^{\text {th }}$ post-operative day. Median hospital length of stay was $7.4 \pm 5.2$ days (range 2 to 31 days). Fifteen children (14.7\%) were re-admitted to the hospital, 11 because of nonspecific abdominal pain and 3 because of an intra-abdominal abscess. All were treated conservatively.

\section{Predictors of postoperative complications}

Univariate analysis identified 4 parameters as independent predictors of a longer hospital stay (as continuous variable): CRP level $>10 \mathrm{mg} / \mathrm{dL}$, fever $\left(\geq 38^{\circ} \mathrm{C}\right)$ at admission, long duration of fever ( $\geq 2$ days) prior to admission, and long duration of symptoms ( $\geq 3$ days) prior to admission (Table 3 ). All parameters were entered into the multivariable analysis, in addition to age and gender (Table 4). Parameters found to be independently associated with longer hospital stay were CRP $>10 \mathrm{mg} / \mathrm{dL}$ (OR 20.657; 95\% Cl 1.790-238.369, $P=0.016$ ) and long fever duration ( $\geq 2$ days) before admission (OR 2.837; $95 \% \mathrm{Cl} 0.305-26.43, P=0.03)$. None of the parameters was significantly associated with abscess formation or wound site infection, and neither as function of peritoneal culture isolates.

\section{Discordance between surgical and pathological diagnosis}

In 12 cases (11.7\%), the surgical diagnosis was simple (acute or phlegmonous) appendicitis (Table 5), and the patients were therefore treated with a short course of empir- 
ical antibiotics, before receipt of the pathological diagnosis of complex appendicitis (gangrenous in all, with no perforation). This subgroup had a relatively low rate of postoperative complications, with only 2 fever episodes in 1 patient each $(1.96 \%)$ and no cases of abscess formation or wound site infections or need for re-admission.

\section{Discussion}

Identifying predictors of postoperative complications of complex appendicitis will help surgeons identify patients at risk who require more stringent monitoring and alert them to the potential need for early intervention and management. The present study of 102 children with complex appendicitis identified 2 parameters that may serve as independent preoperative predictors of longer postoperative hospital stay: CRP level $>10 \mathrm{mg} / \mathrm{dL}$ and fever for $\geq 3$ days prior to admission. These findings are in concordance with previous studies [9-11]. Other previously identified risk factors for postoperative complications were not confirmed in this study, namely, younger age [12], female sex [13] and high white blood cell and absolute neutrophil counts $[9,10,14]$. Obesity or increased body mass index has also been linked to postoperative complications [3,15], but analysis of this factor was unfeasible in this study owing to insufficient data in the medical charts. We were also unable to address other factors such as race, co-morbidities, parameters of the blood chemistry screen and imaging findings, warranting further studies.

Peritoneal cultures were positive in $50 \%$ of the cohort. This rate falls within the range reported in the literature of $24 \%$ to $93 \%[5,16,17]$. Microorganisms belonging to the Enterobacteriaceae family were most often isolated, the majority belonging to the $E$. coli genus (34.4\%), followed by $P$. aeruginosa (16.7\%) and streptococcal species (10\%). Accordingly, the corresponding rates of isolation of these pathogens reported in the literature were $30.8-70 \%, 5.3-$ $19 \%$ and $7-34 \%[6,11,18]$. Our findings did not support an association between specific peritoneal isolates and postoperative complications, suggesting that while intraoperative peritoneal swabs collection may be done for epidemiological purposes or for re-evaluation of empirical treatment, it need not necessarily be part of routine practice.

Determining the appendicitis disease severity intraoperatively is thought to be essential for proper postoperative management, for example, selecting antibiotic therapy in complicated cases. Whether the conventional triple antibiotic regimen (ampicillin, gentamicin and clindamycin) or dual therapy (ceftriaxone with metronidazole) is preferred remains controversial. Several recent studies have found the dual regimen, which is used in our institute, to be more efficient and cost effective [19]. Sometimes, however, the intraoperative impression of the surgeon does not match the pathological diagnosis $[1,20,21]$. In the present study, 12 children were identified intraoperatively as having simple appendicitis and treated accordingly, and only subsequently categorized as having complex appendicitis on receipt of the pathology report. This group had a relatively low rate of postoperative complications and short hospital stay, with- out re-admissions. Although their number was small and the difference was not statistically significant, these results may imply that the intraoperative diagnosis might better predict outcome and clinical course than the pathological diagnosis. This has also been previously suggested in the literature $[22,23]$. In all the discrepant cases, the pathological diagnosis was based on a finding of gangrene. Thus, there may be a need for a third categorization/treatment approach beyond the simple/acute versus complex appendicitis [21,24]. These findings should prompt a trial testing the effectiveness acute simple appendicitis protocols for the treatment of patients with operative findings of gangrenous appendicitis without localized peritonitis.

The present study was limited by the retrospective design with its inherent selection and information biases. Moreover, the study group was relatively small and the study period short, limiting the generalizability of the results. Larger multicenter prospective observational studies are needed to corroborate our findings.

In conclusion, this study of children with a pathological diagnosis of complex appendicitis identified two parameters that were independently predictive of longer hospital stay: CRP $>10 \mathrm{mg} / \mathrm{dL}$ and fever for $\geq 3$ days prior to admission. These factors may help define a high-risk subgroup of children prone to complications who will likely benefit from early detection and intervention for potential complications. In cases of a gangrenous appendix in the absence of local peritonitis, the intraoperative diagnosis may better predict outcome than the pathological diagnosis, suggesting that affected patients may be treated by the same protocol used for acute/simple appendicitis. Obtaining an intraoperative peritoneal swab need not be part of routine practice although it may still be useful for purposes of epidemiological analysis or re-evaluation for empirical treatment.

\section{Funding}

This research did not receive any specific grant from funding agencies in the public, commercial, or not-forprofit sectors.

\section{Conflict of Interest}

The authors declare that they have no conflict of interest.

\section{Ethical Approval}

All procedures performed in studies involving human participants were in accordance with the ethical standards of the institutional and/or national research committee and with the 1964 Helsinki declaration and its later amendments or comparable ethical standards. For this type of study, formal consent is not required.

\section{References}

1. Fallon S, Kim M, Hallmark C, et al. (2015) Correlating surgical and pathological diagnoses in pediatric appendicitis. J Pediatr Surg 50: 638-641.

2. St Peter SD, Sharp SW, Holcomb GW 3rd, et al. (2008) An evidence-based definition for perforated appendicitis derived from a prospective randomized trial. J Pediatr Surg 43: 2242-2245. 
3. Fike FB, Mortellaro VE, Juang D, et al. (2011) The impact of postoperative abscess formation in perforated appendicitis. J Surg Res 170: 24-26.

4. Pittman-Waller VA, Myers JG, Stewart RM, et al. (2000) Appendicitis: Why so complicated? Analysis of 5,755 consecutive appendectomies. Am Surg 66: 548-554.

5. Gladman MA, Knowles CH, Gladman L, et al. (2004) Intra-operative culture in appendicitis: traditional practice challenged. Ann R Coll Surg Engl 86: 196-201.

6. Guillet-Caruba C, Cheikhelard A, Guillet M, et al. (2011) Bacteriologic epidemiology and empirical treatment of pediatric complicated appendicitis. Diagn Microbiol Infect Dis 69: 376-381.

7. Kenig J, Richter P (2013) The need for culture swabs in laparoscopically treated appendicitis. Wideochir Inne Tech Maloinwazyjne 8: 310-314.

8. Horan TC, Andrus M, Dudeck MA (2008) CDC/NHSN surveillance definition of health care-associated infection and criteria for specific types of infections in the acute care setting. Am J of Infect Control 36: 309-332.

9. Chen CL, Chao HC, Kong MS, et al. (2017) Risk factors for prolonged hospitalization in pediatric appendicitis patients with medical treatment. Pediatr Neonatol 58: 223-228.

10. Obayashi J, Ohyama K, Manabe S, et al. (2015) Are there reliable indicators predicting post-operative complications in acute appendicitis? Pediatr Surg Int 31: 1189-1193.

11. Obinwa O, Peirce C, Cassidy M, et al. (2015) A model predicting perforation and complications in paediatric appendicectomy. Int J Colorectal Dis 30: 559-565.

12. Lo H-C, Chien W-K, Huang C-S, et al. (2016) Does age affect the outcomes and management of pediatric appendicitis in Taiwan? Formosan Journal of Surgery 495: 174-177.

13. van Wijck K, de Jong JR, van Heurn LW, et al. (2010) Prolonged antibiotic treatment does not prevent intra-abdominal abscesses in perforated appendicitis. World J Surg 34: 3049-3053.
14. Emil S, Elkady S, Shbat L, et al. (2014) Determinants of postoperative abscess occurrence and percutaneous drainage in children with perforated appendicitis. Pediatr Surg Int 30: 1265-1271.

15. Garey CL, Laituri CA, Little DC, et al. (2011) Outcomes of perforated appendicitis in obese and nonobese children. J Pediatr Surg 46: 2346-2348.

16. Maltezou HC, Nikolaidis P, Lebesii E, et al. (2001) Piperacillin/ tazobactam versus cefotaxime plus metronidazole for treatment of children with intra-abdominal infections requiring surgery. Eur J Clin Microbiol Infect Dis 20: 643-646.

17. McNamara MJ, Pasquale MD, Evans SR (1993) Acute appendicitis and the use of intraperitoneal cultures. Surg Gynecol Obstet 177: 393-397.

18. Schmitt F, Clermidi P, Dorsi M, et al. (2012) Bacterial studies of complicated appendicitis over a 20-year period and their impact on empirical antibiotic treatment. J Pediatr Surg 47: 2055-2062.

19. Dreznik Y, Feigin E, Samuk I, et al. (2018) Dual versus triple antibiotics regimen in children with perforated acute appendicitis. Eur J Pediatr Surg 28: 491-494.

20. Cho J, Lee D, Sung K, et al. (2017) Clinical implication of discrepancies between surgical and pathologic diagnoses of acute appendicitis. Ann Surg Treat Res 93: 43-49.

21. Emil S, Gaied F, Lo A, et al. (2012) Gangrenous appendicitis in children: a prospective evaluation of definition, bacteriology, histopathology, and outcomes. J Surg Res 177: 123-126.

22. Colleran G, Heneghan H, Sweeney KJ, et al. (2007) A comparison of surgical impression, histological findings and microbiological results at open appendicectomy. Ir Med J 100: 593-596.

23. Farach SM, Danielson PD, Walford NE, et al. (2015) Operative findings are a better predictor of resource utilization in pediatric appendicitis. J Pediatr Surg 50: 1574-1578.

24. Shbat L, Emil S, Elkady S, et al. (2014) Benefits of an abridged antibiotic protocol for treatment of gangrenous appendicitis. J Pediatr Surg 49: 1723-1725. 